\title{
Fordismo, pós-fordismo e ciberfordismo: os (des)caminhos da Indústria 4.0
}

\section{ana paula paes de Paula ${ }^{1}$ KetLle DuARte Paes ${ }^{2}$}

\author{
${ }^{1}$ Universidade Federal de Minas Gerais (UFMG), Belo Horizonte - MG, Brasil
}

${ }^{2}$ UnIVERsidade Federal DE RIO GRANDE (FURG), RIO GRANDE - RS, BRASIL

\begin{abstract}
Resumo
O objetivo deste artigo é abordar a Indústria 4.0 como o cerne de um novo paradigma de produção - o ciberfordismo - que emergiu no bojo do estágio ultraneoliberal do capitalismo. Primeiramente, apresentamos as características da Indústria 4.0 para evidenciar como ela radicaliza os processos de automação da produção e de inserção da inteligência artificial nos processos decisórios. Em seguida, retomamos os contornos dos paradigmas fordistas e pós-fordistas de produção, demarcando a continuidade entre estes e o ciberfordismo, bem como apontando a desconstrução do compromisso fordista e do Estado de bem-estar em sua transição para os modelos de flexibilização pós-fordistas e neoliberais. Discutimos também as características do paradigma ciberfordista, que maximiza os propósitos do fordismo clássico, uma vez que tende a tornar prescindíveis a mão de obra qualificada e até mesmo os próprios gerentes. Na conclusão, destacamos as contribuições do artigo e recomendações para futuras pesquisas.
\end{abstract}

Palavras-chave: Fordismo. Pós-fordismo. Ciberfordismo. Indústria 4.0.

\section{Fordism, post-fordism, and cyberfordism: the paths and detours of Industry 4.0}

\section{Abstract}

This article approaches Industry 4.0 as the core of cyberfordism, a new production paradigm that emerged amid the ultra-neoliberal stage of capitalism. The first part of the study presents the characteristics of Industry 4.0, showing how it radicalizes production automation and inserts artificial intelligence in decision-making processes. The second part returns to the Fordist and post-Fordist production paradigms, demarcating the continuity between them and cyberfordism. We point out the deconstruction of the Fordist commitment and the welfare state during the transition to post-Fordist and neoliberal flexibilization models. In the third part, we discuss the characteristics of the cyberfordist paradigm, which maximizes the purposes of classic Fordism since it tends to make skilled labor and managers unnecessary. In the conclusion, we highlight the contributions and recommendations for future research.

Keywords: Fordism. Post-Fordism. Cyberfordism. Industry 4.0.

\section{Fordismo, posfordismo y ciberfordismo: los (des)caminos de la Industria 4.0}

\section{Resumen}

El propósito de este artículo es abordar la Industria 4.0 como el núcleo de un nuevo paradigma de producción, el ciberfordismo, que surgió en medio de la etapa ultraneoliberal del capitalismo. En la primera parte, presentamos las características de la Industria 4.0 para mostrar cómo radicaliza los procesos de automatización de la producción y de inserción de inteligencia artificial en los procesos de toma de decisiones. En la segunda parte, volvemos a los contornos de los paradigmas de producción fordista y posfordista, delimitando la continuidad entre estos y el ciberfordismo, y señalando la deconstrucción del compromiso fordista y el estado de bienestar en su transición a modelos de flexibilización posfordistas y neoliberales. En la tercera parte, discutimos las características del paradigma ciberfordista, que maximiza los propósitos del fordismo clásico, ya que tiende a hacer innecesaria la mano de obra calificada e incluso los propios gerentes. En las conclusiones destacamos los aportes del artículo y las recomendaciones para futuras investigaciones.

Palabras clave: Fordismo. Posfordismo. Ciberfordismo. Industria 4.0. 


\section{INTRODUÇÃO}

Nos últimos anos, a indústria 4.0 emergiu como uma espécie de panaceia no mundo industrial e corporativo, dando origem a expectativas de uma revolução no campo produtivo e também a derivados como a Gestão 4.0, a Produção 4.0, a Qualidade 4.0, a Economia 4.0, entre outros. Em linhas gerais, a Indústria 4.0 (Oesterreich \& Teuteberg, 2016; Zawadzki \& Żywicki, 2016) busca transformar a comunicação entre homens e máquinas e entre as próprias máquinas, utilizando informações para otimizar os processos produtivos, a fim de alcançar um maior grau de uso das tecnologias digitais e da automação, recorrendo à inteligência artificial, big data e machine learning, de modo a tornar a produção mais ágil, econômica e autônoma.

O fenômeno pode ser considerado como mais uma representação do processo da Revolução Industrial, iniciado no final do século XVIII, que marcou a transição dos métodos de produção artesanais para processos de produção mecanizados. Essas mudanças progressivas revolucionaram não só a vida cotidiana das pessoas, mas a economia, com o aumento da produtividade. Desde então, as sociedades modernas têm passado por diversos ciclos de transformação, tanto em sistemas econômicos, quanto de produção e de gestão. Segundo Hermann, Pentek e Otto (2016), passamos por quatro revoluções industriais; a última é marcada pela Indústria 4.0 .

Constatamos, tanto em nossa pesquisa, como nas escassas investigações encontradas, que na literatura ainda são raras as análises sobre o fenômeno da Indústria 4.0 no campo da Teoria da Administração e das organizações, pois suas atividades e características são estudadas principalmente nas áreas de Engenharia, Administração da Produção e Ciência da Computação. A ascensão do tema, no entanto, vem gerando muitos questionamentos por parte de discentes em sala de aula, na graduação e pós-graduação, sobre como a Indústria 4.0 enquadra-se nos modelos de organização e produção, de modo que a ausência de uma abordagem e literatura específicas vem criando dificuldades didáticas e pedagógicas para os docentes da área.

Neste artigo, nosso objetivo é tentar suprir essa lacuna, abordando a Indústria 4.0 como manifestação de um novo paradigma de produção, que emergiu no bojo do estágio ultraliberal do capitalismo e que denominaremos ciberfordismo. Dessa forma, mais que um potencial novo "modismo gerencial", a Indústria 4.0 representa uma nova forma de organizar e otimizar o trabalho, fruto de uma visão de mundo econômica, social e política específica, inserida em um novo ciclo de "revolução industrial e tecnológica".

Tendo em vista o propósito de teorização do ciberfordismo, este artigo foi estruturado da seguinte maneira: na segunda seção, tomamos como ponto de partida um levantamento bibliográfico, para, então, discutir as características da Indústria 4.0, com o intuito de evidenciar como ela radicaliza os processos de automação da produção e de inserção da inteligência artificial nos processos decisórios. Na terceira, retomamos na literatura os contornos dos paradigmas fordistas e pós-fordistas de produção para demarcar a continuidade entre estes e o ciberfordismo e apontar a desconstrução do compromisso fordista e do Estado de bem-estar em sua transição para os modelos de flexibilização pós-fordistas e neoliberais, que afetam tanto processos produtivos como as feições da condução econômica, social e política das sociedades. Na quarta seção, discutimos as características do que estamos denominando paradigma ciberfordista, o qual se manifesta no contexto do ultraneoliberalismo, maximizando os propósitos do fordismo clássico, uma vez que tende a tornar prescindíveis a mão de obra qualificada e até mesmo os próprios gerentes. Além disso, elaboramos um quadro comparativo dos paradigmas fordista, pós-fordista e ciberfordista, de modo a evidenciar as diferenças e continuidades entre eles. Finalizando, trazemos as conclusões do artigo, destacando suas contribuições e recomendações para futuras pesquisas.

\section{SOBRE A INDÚSTRIA 4.0}

O levantamento bibliográfico realizado na internet e nos bancos de periódicos (Portal Capes, Google Acadêmico, Ebsco, Scopus-Elsevier) com a palavra-chave 'Indústria 4.0' teve como propósito localizar os principais artigos e pesquisas sobre o tema e, com isso, estabelecer um ponto de partida para a discussão pretendida. Importante destacar que não tivemos como propósito realizar estatísticas, revisões sistemáticas, ou bibliometrias, mas enfatizar os trabalhos mais relevantes e referenciados pelos próprios pesquisadores. Essa delimitação bibliográfica tem um caráter didático, considerando as lacunas existentes na literatura para a discussão do tema em sala de aula, em um sentido pedagógico, pois busca responder também as indagações básicas dos discentes sobre o conceito e escopo da Indústria 4.0 no contexto de disciplinas como teoria da administração e das organizações. 
Efetuando essas buscas, encontramos artigos-chave utilizados pela maioria dos pesquisadores - principalmente em domínios em que a presença da Indústria 4.0 se faz sentir, como na engenharia e administração da produção e na ciência da computação -, bem como alguns artigos que trazem sistematizações da literatura sobre o tema. São, portanto, raras as referências ao campo da Teoria da Administração e Organizações. Assim, apesar de haver um grande número de publicações sobre o tema Indústria 4.0, mesmo internacionalmente elas estão dispersas em revistas de diferentes qualificações e níveis de impacto e em várias áreas.

A pesquisa feita por Piccarozzi, Aquilani e Gatti (2018), que realizaram uma revisão sistemática da literatura sobre a Indústria 4.0 na área da Administração, por meio de um levantamento em três bases de dados científicas (Scopus-Elsevier, Web of Science e JStor) e uma ferramenta de busca (Google Scholar) com a palavra-chave 'industry 4.0' confirmam nossas constatações. Em apenas 68 artigos encontrados, nenhum se dedica aos aspectos gerenciais e organizacionais da Indústria 4.0, predominam aspectos técnicos e do campo da Engenharia, o que reafirma que se trata de um tema emergente e pouco explorado na área de Administração. Sigahi e Andrade (2017), por exemplo, ratificam tal constatação, pois ao realizarem uma bibliometria para verificar artigos publicados entre 2011 (ano de surgimento da expressão "indústria 4.0" na Alemanha) e 2016 no ENEGEP (Encontro Nacional de Engenharia da Produção) e no SIMPEP (Simpósio de Engenharia da Produção), constataram que 72\% dos artigos concentravam-se nas áreas de Gestão da Produção, Gestão do Conhecimento Organizacional, Gestão do Produto e Pesquisa Operacional, e que $70 \%$ dos artigos abordavam principalmente temas afeitos à ciência da computação, como inteligência artificial, computação em nuvem e internet das coisas.

Já o levantamento realizado por Assad, Pereira, Drozda e Santos (2018), que realizaram uma revisão integrativa do tema Indústria 4.0 na base Scopus-Elsevier, mostra uma liderança da Alemanha na produção acadêmica - o que condiz com o fato de o fenômeno ter surgido neste país -, seguida no ranking pelos Estados Unidos e pela China. Além disso, os pesquisadores concluíram que há ainda uma imprecisão na definição científica de Indústria 4.0, que ainda não constituiu uma identidade mais sólida, o que dificulta também a delimitação de um "estado da arte" sobre o tema. Tessarini e Saltorato (2018), por sua vez, procederam a uma revisão sistemática da literatura sobre o impacto da Indústria 4.0 na organização do trabalho, concluindo que, de um modo geral, as pesquisas enfatizam muito mais suas inovações tecnológicas do que suas implicações nas relações de trabalho. Dessa forma, o que a literatura consultada evidencia é que os estudos encontram-se em um estado inicial: trata-se de um campo em construção, que ainda busca descrição e definição do fenômeno. Em seguida, com intuito de cumprir o aspecto didático deste texto, bem como situar os conceitos fundamentais do tema tratado, apresentamos, de forma sintética, as principais características da Indústria 4.0 e algumas de suas repercussões no setor industrial, tendo como base os artigos-chave examinados.

Segundo Anderl (2014) e Silva e Santos e Miyagi (2015), a Indústria 4.0 busca a integração de humanos e máquinas, afetando toda a cadeia organizacional, uma vez que atinge a manufatura, o projeto, os produtos e as operações por meio de sistemas que acessam dados em tempo real para realizar ações autônomas. Objeto de estudos recentes (Gentner, 2016; Qin, Liu \& Grosvenor, 2016; Roblek, Mesko \& Krapez, 2016), constitui um campo de conhecimento que abrange Administração, Engenharia e Ciência da Computação, entre outros, representando, de acordo com Bitkom, Vdma e Zvei (2016), Drath e Horch (2014), Hermann, Pentek e Otto (2015), Kubinger e Sommer (2016) e Schwab (2016), uma Quarta Revolução Industrial, que emergiu na Alemanha apoiada pelo governo federal.

Schwab (2016) caracteriza a Quarta Revolução Industrial como uma nova era tecnológica que implicará a robotização da humanidade, transformando fontes tradicionais de significado como trabalho, família, comunidade e identidade. Para o autor, os efeitos distributivos disso podem favorecer o capital, mas ele questiona se realmente interessará à humanidade um mundo do "precariado", que resultaria em uma grande fonte de agitação social e política. Antunes (2019) é menos otimista, afirma que, no bojo dessa Quarta Revolução Industrial, emergiu a Indústria 4.0, que tende a realizar uma imbricação entre a financeirização da economia e um neoliberalismo exacerbado, intensificando as tecnologias digitais no mundo da produção nessa nova fase do capitalismo, na qual as formas de controle social serão reacomodadas.

Apresentando um ponto de vista técnico, Santos, Alberto, Lima e Charrua-Santos afirmam que (2018, p. 115) “[...] a Indústria 4.0 representa uma evolução natural dos sistemas industriais anteriores, de desde a mecanização do trabalho ocorrida no século XVIII até a automação da produção nos dias atuais." Com a evolução da automação e dos sistemas de informação por meio do ERP (Enterprise Resource Planning) e do MES (Manufacturing Execution System), a produtividade nas fábricas melhorou significativamente, mas ainda há uma lacuna na comunicação entre o nível ERP e o chão de fábrica, cuja solução pode estar no aprimoramento da tomada de decisão em tempo real proporcionada pela Indústria 4.0, que promete (Kargermann, 2014; 
Kargermann, Wahstler \& Helbig, 2013) maior eficácia operacional e ganhos de produtividade, crescimento e competividade, além do desenvolvimento de novos modelos de negócios, serviços e produtos.

De acordo com Hermann, Penteck e Otto (2016), a Indústria 4.0 é composta por:

- Sistemas Ciberfísicos (Cyber-Physical Systems [CPS]): integram os objetos físicos e seus modelos, representados em redes, bem como serviços baseados nos dados disponíveis;

- Internet das Coisas (Internet of Things [IOT]): constrói uma rede de comunicação entre pessoas e dispositivos, utilizando objetos de nosso cotidiano a fim de tornar a internet ubíqua;

- Internet de Serviços (Internet of Services [IOS]): utiliza a estrutura da internet para possibilitar a oferta e a demanda de serviços;

- Fábricas Inteligentes: baseiam-se na conectividade da IOT e na disponibilização da IOS, gerenciando sistemas complexos que integram máquinas e humanos em uma rede, cujas plantas têm suas demandas realizadas pelos CPSs e se comunicam pela IOT.

Dessa forma, a Indústria 4.0 mobiliza conceitos como auto-organização, novos sistemas de distribuição e aquisição, novos sistemas de desenvolvimento de produtos e serviços, adaptação das necessidades humanas e da responsabilidade social da corporação (Lasi, Fettke, Kemper, Feld \& Hoffmann, 2014). A Indústria 4.0 exigirá transformações na organização do trabalho no que tange à flexibilização da produção para customização e redução de custos, bem como nas habilidades dos trabalhadores diante das novas interfaces homem-máquina, que exigem reconhecimento de voz e gestos (Khan \& Turowski, 2016).

Além disso, a Indústria 4.0 sustenta-se por nove pilares tecnológicos (Rübmann et al., 2015):

- Big data e análise de dados (obtidos, em massa, de diversas fontes e utilizados para decisões em tempo real);

- Robôs autônomos trabalhando ao lado de humanos;

- Simulação para tomada de decisão;

- Integração horizontal e vertical de sistemas que facilitam redes intercompanhias e automação;

- IOT mobilizada para obtenção de respostas em tempo real;

- Segurança cibernética;

- Nuvem;

- Fabricação de aditivos (produtos customizados e utilização de impressoras 3D); e

- Realidade aumentada, na qual a tomada de decisão e os procedimentos são auxiliados por uma grande variedade de sistemas atuando conjuntamente.

Segundo Pereira e Simonetto (2018), uma publicação da Firjan (Federação das Indústrias do Estado do Rio de Janeiro [Firjan], 2016) evidenciou que o Brasil ainda se encontra entre a Segunda e Terceira Revolução Industrial - o setor automotivo é o mais adiantado em relação à Indústria 4.0. Os desafios para a sua implantação no Brasil envolvem políticas e incentivos governamentais estratégicos, postura proativa de empresários e gestores, além do desenvolvimento de tecnologias e capacitação de profissionais alinhados com essa visão de indústria (Vermulm, 2018). Para Kupfer (2016), embora no Brasil o debate ainda seja tímido e haja poucas iniciativas, além de a indústria nacional ainda se encontrar principalmente no estágio 2.0, a Indústria 4.0 é mais simples de ser implementada do que parece, porque se trata mais de escalagem e massificação do uso de integração de tecnologias já disponíveis, e menos de desenvolvimento inovativo propriamente dito.

Do ponto de vista do desempenho operacional da Indústria 4.0, Tortorella, Fetterman, Giglio e Borges (2018) evidenciam que, para pesquisadores como Marodin e Saurin (2013), Shah e Ward (2003), Jasti e Kodali (2016), as práticas enxutas e sobrepostas aplicadas na organização e em sua cadeia de suprimentos trariam melhorias. No entanto, Tortorella et al. (2018) examinam em sua pesquisa a relação entre a implementação de práticas de produção enxuta e da Indústria 4.0 para verificar sua influência no desempenho operacional organizacional. Os autores concluem que ainda não é possível constatar uma melhoria relevante, talvez devido a falhas de implementação e variáveis contextuais negativas. Assim, essa integração entre 
as práticas de produção enxuta e as tecnologias da Indústria 4.0, que teoricamente possibilita maior flexibilidade e fluxo de informações e vem sendo denominada "automação enxuta", ainda precisa ser mais explorada, conforme afirmam Erol, Schumacher e Sihn (2016) e Sanders, Elangeswaran e Wulfsberg (2016).

Por outro lado, Saltiél \& Nunes (2017) evidenciam que a automação é uma forma de minimizar a dependência em relação aos trabalhadores em um contexto no qual as relações capital e trabalho mostram-se cada vez mais instáveis, além de dispensar suas habilidades. A Indústria 4.0 firma-se, dessa forma, como uma nova revolução industrial, uma vez que mobiliza três elementos principais - rede de produção e de produto, ciclo de vida do produto e sistemas ciberfísicos -, resultando em ciclos cada vez menores, que podem ser gerenciados técnica e economicamente.

Tessarini e Salltorato (2018) estudam a discussão na literatura dos impactos da Indústria 4.0 na organização do trabalho e constatam o aumento do desemprego tecnológico, apontando a necessidade de novas competências para que sejam mantidas as condições de empregabilidade. Além disso, verificam um aumento na interação homem e máquina, bem como transformações nas relações socioprofissionais. Os pesquisadores apontam, ainda, baseados em Caruso (2018), que a tendência é de que o poder de decisão e a autonomia dos trabalhadores diminuam, intensificando-se a redução da força de trabalho, a redução dos direitos e garantias dos trabalhadores, bem como a concentração do capital e o monopólio das forças de produção, com a crescente precarização das relações de trabalho e o aumento da hegemonia das máquinas.

Em síntese, podemos afirmar que a Indústria 4.0 representa:

- Uma manifestação da Quarta Revolução Industrial, que estabelece mudanças tecnológicas mediadas pela robotização e inteligência artificial, implicando grandes transformações no campo produtivo e do trabalho, desdobrando-se, ainda, em reelaboração dos efeitos distributivos nas sociedades, que reforçam um novo ciclo do capitalismo;

- Uma integração entre os sistemas ciberfísicos e a internet das coisas e de serviços, que promove um salto tecnológico para habilitar a rede de operação de fábricas inteligentes, utilizando robôs autônomos e simuladores de decisão, prescindindo cada vez mais da mão de obra humana;

- Um desafio em promover nos vários países, incluindo o Brasil, uma conexão entre os sistemas automatizados e digitais da Indústria 3.0, que engendram a "automação enxuta" e as mediações da internet trazidas pela Indústria 4.0, promotoras de novas formas de produção e distribuição de produtos e serviços, bem como novos modelos de negócios.

\section{FORDISMO E PÓS-FORDISMO}

Ainda que o tema não tenha sido suficientemente explorado no campo da Teoria da Administração e Organizações, uma vez que, como anteriormente mencionado, os estudos encontrados são predominantemente da área de Engenharia e Administração da Produção e Ciência da Computação, alguns pesquisadores já começam a designar a Indústria 4.0 como um "novo paradigma de produção" (Lima \& Pinto, 2019; Silva et al., 2015), ou seja, uma nova lógica de produção, que recorre a novas tecnologias e formas de organização.

No levantamento bibliográfico, destaca-se um artigo emblemático para a área de organizações, de Wood (1992), que comparou os paradigmas clássicos de produção baseando-se na indústria automobilística: o fordismo, o toyotismo e o volvismo. Em geral, o toyotismo, alicerçado no modelo japonês de administração, é considerado na literatura um modelo pós-fordista ou neofordista de produção. Alves, Marx e Zilbovicius (1992), por exemplo, questionavam em sua época se as transformações introduzidas nas linhas de produção industrial seriam de fato uma transformação radical do paradigma fordista ou se representariam uma evolução gradual do mesmo paradigma. De acordo com Kupfer (2016), é possível fazer uma analogia entre a Indústria 4.0 com o que nos anos 1980 denominamos pós-fordismo, toyotismo, produção enxuta ou qualidade total - tecnologias organizacionais que dizem respeito à forma como se produz. Para Tenório e Valle (2012), há um continuum entre fordismo e pós-fordismo que abriga várias possibilidades e combinações tecnológicas, alternando rigidez e flexibilidade, de modo que mais do que antítese, temos entre eles uma síntese, como evidenciam os autores utilizando como exemplo a "fábrica de software". Dessa forma, com base na literatura, podemos afirmar que, para além da ideia de inovação e transformação de paradigmas, há uma espécie de continuum entre o fordismo, o pós-fordismo e a Indústria 4.0. 
A emergência do fordismo tem estreitos laços com os princípios do taylorismo, que estabeleceu a clássica separação entre planejamento e execução, bem como uma detalhada divisão do trabalho, para que houvesse ganhos de eficiência e produtividade nas fábricas. Esses princípios obedecem a uma forte padronização de tempos e movimentos, a uma rigorosa separação entre o trabalho manual e intelectual e ao controle de tempo de cada operação, dentre outras técnicas e processos de trabalho.

Esse modelo de produção estabeleceu-se como hegemônico até os anos 1970, tendo como ambiente para o seu desenvolvimento o suporte das políticas macroeconômicas do keynesianismo. O fordismo, sobretudo, após a Segunda Guerra Mundial, garantiu um dos mais longos períodos de crescimento estável do sistema capitalista, cuja duração foi de aproximadamente 30 anos, quando, então, o modelo começou a dar sinais de esgotamento. Cabe observar ainda que, durante o período de expansão do fordismo, os ganhos de produtividade do modelo foram, em boa parte, repassados para os assalariados, tanto de forma direta, como aumento dos salários, quanto indireta, por meio do Estado do bem-estar social keynesiano (Lipietz, 1991).

Como já mencionamos, o modelo de gestão do fordismo também foi alvo de estudos no campo da Administração por trazer inovações importantes para os ganhos de produtividade (Wood, 1992). Essas inovações permitiram reduzir o esforço humano na montagem, aumentar a produtividade e diminuir os custos. Além disso, o modelo conseguiu reduzir drasticamente o tempo de preparação das máquinas, possibilitando que elas executassem apenas uma tarefa por vez, pois eram colocadas em uma sequência lógica; seu principal problema era a falta de flexibilidade. O fordismo, na visão de Harvey (1993), obteve êxito por reconhecer que a produção de massa significava consumo de massa e gerou um novo tipo de organização do trabalho e da sociedade.

Conforme apontamos, o sistema produtivo fordista começa a apresentar sinais de esgotamento a partir dos anos 1970. Na visão de Antunes (1995), tratou-se de uma crise estrutural que se caracterizou pela queda na taxa de lucros, pelo desemprego estrutural causado por uma retração do consumo e pela crise do Estado do bem-estar social. Tal crise ocorreu como desdobramento da crise fiscal do Estado capitalista, que engendra o ideário de Estado mínimo neoliberal. Assim, a década de 1980 presenciou profundas transformações na estrutura produtiva com a inserção de novas tecnologias, como a automação, a robótica e a microeletrônica. Trata-se de uma época de grande experimentação no mundo do trabalho, no qual o fordismo e o taylorismo já não são únicos e misturam-se com outros processos produtivos chamados pós-fordistas.

Segundo Lipietz (1991), o modelo de produção pós-fordista, mais especificamente, o toyotismo, surgiu ao final da década de 1970, com a eclosão da chamada Terceira Revolução Industrial, implementada com a chegada ao poder de Margareth Thatcher, na Inglaterra, e Ronald Reagan, nos Estados Unidos. Ambos preparam o terreno para o estabelecimento do Estado mínimo, circundado por processos de privatização, terceirizações e ajustes fiscais. Este novo paradigma de produção apoiou-se sobre os ombros do fordismo em crise, para dar vazão a uma revolução tecnológica no âmbito dos processos produtivos.

De um modo geral, Antunes (1995) relata que o toyotismo é um modelo de organização do trabalho que nasce na fábrica Toyota, no Japão, e que se expandiu pelo Ocidente capitalista, tanto nos países avançados, quanto naqueles em desenvolvimento. Seguindo essa lógica de argumentação, o modelo toyotista representou uma oposição à rigidez do modelo fordista, adotando a especialização flexível na busca por novos padrões de produtividade, por novas formas de adequação da produção à lógica do mercado. Como consequência, tem-se também a emergência de novas formas de gestão da força de trabalho, dentre as quais os Círculos de Controle de Qualidade e a dita gestão participativa são expressões visíveis não só no Japão, mas em vários países do mundo ocidental.

A expansão do pós-fordismo é acompanhada não somente da chamada especialização flexível na esfera da produção, mas também do fim do Estado de bem-estar social e da busca frenética por flexibilização das relações de trabalho mediante práticas de austeridade econômica neoliberais. Assim, no que diz respeito aos direitos trabalhistas, ocorre uma desregulamentação objetivando uma adequação aos novos modos de organização do trabalho. Direitos e conquistas históricas dos trabalhadores são substituídos e eliminados do mundo da produção.

Importa observar, aqui, que os modelos produtivos fordistas e pós-fordistas possuem íntima conexão com os avanços tecnológicos ligados às chamadas Segunda e Terceira Revoluções Industriais (Lipietz, 1991), nos quais o uso dos recursos tecnológicos em escala geométrica tem se transformado na própria força produtiva, em um patamar que busca cada vez mais a dispensa da atividade humana. Como consequência, observa-se o aparecimento do desemprego estrutural, que extirpa postos de trabalho e funções em favor da automação nos processos de trabalho. 
Desse modo, conforme observa Antunes $(1995$, p. 26), para suprir as demandas mais individualizadas de mercado foi preciso que a produção se sustentasse num processo produtivo flexível, que permitisse "[...] a um operário operar com várias máquinas (em média cinco máquinas, na Toyota), rompendo-se com a relação de um homem/uma máquina que fundamenta o fordismo". Essa relação homem-máquina e o amplo uso da tecnologia, típica do fordismo e do pós-fordismo, encontra seu ápice no que vem sendo estudado como Quarta Revolução Industrial, que faz emergir a Indústria 4.0, na qual a interação que importa, em grande medida, é a "máquina-máquina" (M2M). Essa dinâmica M2M segue na direção do que chamaremos, neste artigo, de ciberfordismo.

\section{EMERGE UM NOVO PARADIGMA DE PRODUÇÃO: O CIBERFORDISMO}

Considerando que há um continuum entre o fordismo, o pós-fordismo e a Indústria 4.0, procuramos caracterizar esta última como manifestação de um novo paradigma de produção, que também emerge na indústria automobilística e denominaremos ciberfordismo. Nosso intuito é discutir o ciberfordismo como um modelo "ultrafordista" de produção, no qual os preceitos do fordismo são maximizados com o auxílio da automação, da cibernética e de outras características próprias da emergente Indústria 4.0. Do ponto de vista econômico e social, conforme destaca Antunes (2020a), emerge uma nova morfologia do trabalho, caracterizada por sua "invisibilidade", implicando precarização dos vínculos e de novas formas de exploração potencializadas pelo estágio ultraneoliberal do capitalismo.

Denominamos esse como o estágio ultraneoliberal do capitalismo, pois, de acordo com Dardot e Laval (2016), entre a década de 1980 e o momento atual, o neoliberalismo adquiriu novas facetas, extrapolando a política e a economia neoliberal para fundar uma "sociedade neoliberal" que afeta radicalmente os sistemas de produção. O neoliberalismo, uma decantação do "novo liberalismo" surgido na década de 1930, em sua fase "ultra" é fruto da consolidação de uma racionalidade que se desenvolveu entre as décadas de 1980 e 1990 e fez emergir uma nova racionalidade governamental e empresarial, fundada nos seguintes princípios para o Estado, que se torna um guardião do mercado: estabilidade da política econômica, estabilidade monetária, mercados abertos e concorrência, propriedade privada, liberdade de contratos e responsabilidade dos agentes econômicos.

Surge assim o que Dardot e Laval (2016, p. 140) denominam "economia social de mercado", oposta ao Estado de bem-estar, na medida que responsabiliza individualmente os cidadãos por seu status social e incentiva o empreendedorismo. Assim, o "[...] mercado é concebido [...] como um processo de autoformação do sujeito econômico, um processo subjetivo autoeducador e autodisciplinador, pelo qual o indivíduo aprende a se conduzir". Faz-se também uma passagem do capitalismo neoliberal para o capitalismo financeiro, abrindo espaço para um "capitalismo improdutivo", como assinala Dowbor (2017), cuja base está na "financeirização da economia", ou seja, em um capital "parado", que, apesar de não ser utilizado nas redes produtivas, acumula rendimentos por aplicações especulativas nos mercados de ações.

Recapitulando, de acordo com Wood (1992), o modelo fordista de produção, ao introduzir a linha de montagem, reduziu o esforço humano empregado, aumentou a produtividade e diminuiu os custos, mas resultou na superespecialização do trabalhador. Era um modelo de produção baseado nos princípios tayloristas e na ideia de mecanização, com uma interação precisa entre homem e máquina, verticalização da produção e sistema de controle burocratizado.

Já o pós-fordismo envolve uma série de inovações técnicas que resultavam em uma dramática redução no tempo demandado para alteração dos equipamentos de moldagem, possibilitando a relação entre "homem" e "várias máquinas", bem como a "flexibilização" da produção e o atendimento de um mercado consumidor que buscava diferenciação de produtos - por exemplo: tornou mais barato produzir pequenos lotes de peças estampadas, diferentes entre si, do que grandes lotes homogêneos. Além disso, reduziu custos de inventários (sistema just-in-time), possibilitou melhorias contínuas na produção e eliminou problemas de qualidade, exigindo, no entanto, operários bem treinados e motivados. Na rede de suprimentos, ocorreu uma horizontalização e descentralização, na medida em que eram utilizados muitos fornecedores em uma relação de parceria.

O que estamos denominando ciberfordismo, que parte da Indústria 4.0, é um modelo de produção que preserva as características de flexibilização e busca de qualidade, bem como redução de custos, que exige, no entanto, novas interfaces entre homemmáquina e máquina-máquina, retomando um padrão clássico fordista, uma vez que reduzem a necessidade do trabalho qualificado e mesmo do próprio trabalho humano. Conforme aponta Toni (2019), no contexto da Indústria 4.0, com o uso de processos altamente informatizados e robóticos e de sistemas de controle que centralizam os processos de gerenciamento, 
as organizações podem passar a prescindir não só daqueles que realizam tarefas desqualificadas, mas mesmo daqueles que têm um papel mais especializado. É como se o ideal mecanicista fordista pudesse, enfim, ser plenamente realizado com o uso de robôs autônomos e simuladores de decisões.

Na visão de Kupfer (2016), esse ideal não está tão distante das organizações, já que não se trata de um desenvolvimento inovativo, mas de escalagem da massificação da integração de tecnologias já disponíveis oriundas dos modelos pós-fordistas de produção, que culminaram na Indústria 4.0. Saltiél e Nunes, por sua vez, também admitem que os sistemas ciberfísicos minimizam a participação do trabalhador, que passa a realizar funções mais simples, o que é uma vantagem, uma vez que não está sendo possível extrair voluntariamente o rendimento máximo da força de trabalho. O filme "Indústria Americana", documentário ganhador do Oscar 2020, produzido por Jeff Reichert e Julie Parker Benello e dirigido por Steven Bognar e Julia Reichert (2019), evidencia isso com clareza ao mostrar que, na impossibilidade de obter dos trabalhadores estadunidenses o mesmo rendimento que conseguiam com os chineses, os executivos da Fuyao passam a substituí-los por robôs autônomos.

De acordo com o que sugerem Hermann, Penteck e Otto (2016), as "fábricas inteligentes" recorrem à conectividade da IOT e à disponibilidade da IOS para gerenciar sistemas complexos, que integram em rede máquinas e humanos por meio dos CPSs. A palavra cyber, originária do termo cybernetics, significa uma "grande concentração de tecnologia avançada", que sintetiza o mote em torno desse novo paradigma de produção, denominado por nós como ciberfordismo, que simboliza uma efetivação do intento último de mecanicismo fordista e representa um novo estágio do continuum dos paradigmas de produção: o ultrafordismo.

São ainda praticamente inexistentes as referências ao ciberfordismo na literatura acadêmica, de modo que estamos nos arriscando a inseri-lo no debate e caracterizá-lo. Nossa pesquisa na internet e nos bancos bibliográficos com a palavra-chave "ciberfordismo" (Portal Capes, Google Acadêmico, Ebsco, Scopus Elsevier) resultou em um único trabalho que usa esse termo: a resenha de Toni (2019) - uma análise do livro de Astrologo, Suborne e Terna (2019) - utiliza o termo em um sentido similar ao que estamos apresentando. Seu argumento é de que, por um lado, a Indústria 4.0 abandona o clássico modelo taylorista-fordista com base na hierarquia e na superespecialização de tarefas; mas, por outro, maximiza a memória de Taylor com um modelo ciberfordista que implica o uso da inteligência artificial para realizar esse controle hierárquico e da cadeia de decisão com grande eficiência e drástica redução dos custos de mão de obra.

O diferencial dos sistemas de inteligência artificial, próprios da Indústria 4.0, está no uso de máquinas inteligentes que podem reorganizar a força de trabalho material e intelectual até mesmo substituindo os seres humanos em tarefas mais complexas. Nesse contexto, Astrologo, Suborne e Terna (2019) preveem a emergência de um subproletariado destinado a trabalhos ocasionais e desqualificados, que não podem ser realizados por máquinas, e a substituição de técnicos e trabalhadores que desempenhavam funções de gerenciamento e tarefas especializadas por máquinas inteligentes e sistemas de controle generalizados.

Assim, do compromisso fordista com viés keynesiano conectando a produção e o consumo em massa com apoio do Estado de bem-estar social, cujo auge ocorreu na década de 1960, passamos pelo pós-fordismo de inspiração neoliberal, envolvendo a flexibilização da produção e intensa terceirização dos processos de trabalho, com desmonte do aparato estatal previdenciário nos países ocidentais para alcançar o estágio ultraneoliberal ciberfordista, delimitado pela Indústria 4.0. Este estágio mobiliza, como apontou Antunes (2020a), um proletariado fabril e de serviços precarizados, de período parcial e vínculo temporário, bem como um proletariado informal - um segmento de trabalhadores conhecidos hoje como "uberizados" (por exemplo, entregadores de produtos, motoristas de aplicativos). Ambos são afetados pelos seguintes elementos formativos: a ideologia neoliberal, que destrói a legislação protetora trabalhista, privilegiando o mercado, e uma revolução tecnológica voltada para o capital e não para a humanidade.

Dessa forma, o ideário da Indústria 4.0 atinge tanto o setor industrial quanto o de serviços, alcançando os trabalhadores no home office e também os prestadores de serviços precarizados gerenciados pelas "plataformas digitais". No caso brasileiro, a despeito dos avanços no setor industrial, as pesquisas demonstram que permanecem ainda os paradigmas 2.0 e 3.0. No entanto, tal ideário vem se enraizando de forma acelerada no setor de serviços com as novas tecnologias de informação e comunicação. Antunes (2020b) denomina essa fase como de hegemonia informacional-digital e ciberindustrial, permeada por um discurso de "empreendedorismo" que está edificando uma nova engenharia social para reduzir ao máximo o trabalho humano necessário à produção e substituí-lo por novas tecnologias digitais que engendram a "internet das coisas", o big data e a inteligência artificial, promovendo uma "desantropormofização do trabalho", na medida em que subordina o trabalho real à "máquina-ferramenta-informacional". 
Em síntese, é possível apresentar o seguinte comparativo dos paradigmas de produção (Quadro 1) - fordismo, pós-fordismo e ciberfordismo -, para auxiliar na visualização das diferenças e continuidades entre eles.

\section{Quadro 1}

Comparativo: fordismo, pós-fordismo e ciberfordismo

\begin{tabular}{|c|c|c|c|}
\hline & Fordismo & Pós-Fordismo & Ciberfordismo \\
\hline Nível de mecanicismo & $\begin{array}{l}\text { Homem-Máquina } \\
\text { Rigidez }\end{array}$ & $\begin{array}{l}\text { Homem-Máquinas } \\
\text { Flexibilidade }\end{array}$ & $\begin{array}{l}\text { Máquina-Máquina } \\
\text { Integração Sistêmica }\end{array}$ \\
\hline Nível da mão de obra & $\begin{array}{l}\text { Superespecialização da } \\
\text { mão-de-obra }\end{array}$ & Especialização da mão de obra & Automação da mão de obra \\
\hline $\begin{array}{l}\text { Relação entre operários } \\
\text { e gerentes }\end{array}$ & $\begin{array}{l}\text { Separação entre trabalho } \\
\text { manual e trabalho intelectual }\end{array}$ & $\begin{array}{l}\text { Conexão entre trabalho manual/ } \\
\text { automatizado e trabalho intelectual }\end{array}$ & $\begin{array}{l}\text { Conexão entre trabalho } \\
\text { automatizado e inteligência artificial }\end{array}$ \\
\hline Relação capital-trabalho & Regulamentação do trabalho & Desregulamentação do trabalho & Pós-trabalho \\
\hline Paradigma industrial & Indústria 1.0 e 2.0 & Indústria 3.0 & Indústria 4.0 \\
\hline Paradigma econômico & $\begin{array}{l}\text { Keynesianismo } \\
\text { Estado do bem-estar social }\end{array}$ & $\begin{array}{l}\text { Neoliberalismo } \\
\text { Estado mínimo }\end{array}$ & $\begin{array}{l}\text { Ultraneoliberalismo } \\
\text { Estado guardião do mercado }\end{array}$ \\
\hline
\end{tabular}

Fonte: Elaborado pelos autores.

Ao apontar uma transição da "desregulamentação do trabalho" para o "pós-trabalho", estamos demarcando um momento em que a terceirização, a informalidade, a flexibilidade, a intermitência e a precarização atingem seu ápice, descaracterizando a noção clássica de trabalho assalariado e regulado pela proteção social do Estado, para dar lugar ao que Antunes (2020b) conceitua como uma "subsunção real do trabalho ao capital". Nesse contexto, o ultraneoliberalimo estabelece-se e busca promover uma quase desaparição do Estado, que não atua mais como um regulador para manutenção do bem-estar social, mas como um guardião assumido dos interesses do mercado, como apontam Dardot e Laval (2016).

Assim, apesar de cada paradigma apresentar características peculiares, é possível notar um continuum entre o fordismo, o pós-fordismo e o ciberfordismo, pois fica evidente que cada um representa um estágio do processo de aceleração da Revolução Industrial na direção de uma maior mecanização e desregulamentação do trabalho, sempre de acordo com as novas faces do capitalismo e do paradigma industrial e econômico vigente. Recordando Tragtenberg (1974) e Paes de Paula (2002), as inexoráveis harmonias administrativas seguem seu curso na teoria e prática da gestão, pois, independentemente do paradigma de produção, perpetuam-se os mecanismos diretos e indiretos de controle social, que garantem a produtividade e a ordem nas relações no mundo do trabalho.

\section{CONCLUSÕES}

Neste artigo, nosso objetivo foi abordar a Indústria 4.0 como manifestação de um novo paradigma de produção, o ciberfordismo, destacando suas características e seu alinhamento com o estágio ultraneoliberal do capitalismo. Para isso, delimitamos o que é a Indústria 4.0, ressaltando suas relações com a aceleração da automação industrial e da utilização da internet e inteligência artificial nos processos decisórios. Também debatemos como ocorreu a evolução do fordismo e do pós-fordismo, que se entrelaçam, respectivamente, com o compromisso keynesiano e a flexibilização neoliberal, objetivando demarcar o ciberfordismo como manifestação do estágio ultraneoliberal do capitalismo. Discutimos, então, o paradigma ciberfordista como uma vanguarda renovada do pensamento taylorista-fordista, que, ao maximizar seus propósitos, alcança a realização do sonho mecanicista: tornar dispensáveis tanto a mão de obra fabril, quanto a intervenção gerencial.

Apresentando um quadro sintético com as características do fordismo, do pós-fordismo e do ciberfordismo, evidenciamos que há um continnum entre esses paradigmas de produção, na medida em que representam fases da aceleração dos processos de mecanização e da própria desregulamentação do trabalho. Além disso, os paradigmas de produção refletem visões de mundo que se desdobram em dinâmicas sociais, econômicas e políticas próprias de suas épocas, sem romper com o pressuposto das ideologias e harmonias administrativas responsáveis pelo controle social do trabalho e de sua inserção no contexto produtivo, como demarca o pensamento tragtenberguiano. 
Podemos ainda concluir que o ciberfordismo também é uma manifestação das visões de como se disseminam as novas tecnologias que substituem o trabalho humano, as quais Toni (2019) denomina como tecno-otimistas ou tecno-pessimistas. De um modo geral, o progresso social e econômico tem como justificativa melhorar as condições de vida dos seres humanos, fazendo referência à visão utópica de que a evolução das relações de produção e das tecnologias poderiam levar a uma liberação do trabalho e à emancipação dos sujeitos. No entanto, da forma como atualmente se apresenta, conjugado ao ultraneoliberalismo, o ciberfordismo parece contribuir muito mais para a eliminação de empregos e a precarização das relações de trabalho, sem que ocorra uma contrapartida de liberação da mão de obra fabril e gerencial para outras ocupações, sejam elas produtivas, sociais, políticas e artísticas, que correspondam a uma remuneração necessária a uma sobrevivência digna.

Notamos que, especificamente no caso brasileiro, conforme constatamos na literatura, há muitos desafios para que se alcancem os níveis esperados da Indústria 4.0, pois ainda nos encontramos em estágios anteriores da Revolução Industrial. Embora alguns pesquisadores acreditem que as condições de automação e integração de sistemas já existam, sendo uma questão de articulação e planejamento, o fato é que nossa indústria ainda não apresentou plenamente, em vários casos, os ganhos de produtividade esperados das transformações tecnológicas. Apesar disso, no setor de serviços, esse ideário vem se estabelecendo. No campo das relações de trabalho, observamos a preparação do terreno para uma abordagem ultraneoliberal nos discursos e ações governamentais, assim como nos setores industriais, que estão resultando em reformas cujo resultado foram desregulamentação dos contratos de trabalho e redução de postos de emprego.

No momento em que elaboramos esse texto, o mundo está enfrentando a pandemia causada pelo coronavírus, resultando em isolamento e afastamento social, bem como longos períodos de quarentena para diminuir o ritmo das infecções. O fenômeno nos colocou diante do desafio de implementar de forma acelerada o teletrabalho, o ensino à distância e todos os formatos remotos de atividades que se utilizam de tecnologias de informação como maneira de evitar o contato entre as pessoas. As consequências da pandemia ainda são imprevisíveis, mas é possível especular que contribua para engendrar os processos típicos da Indústria 4.0, em especial a automação e o uso da inteligência artificial nas decisões.

Consideramos que este trabalho, por se tratar de um artigo teórico, alcançou seu objetivo. Discutimos o que foi proposto: as características de um novo paradigma de produção - o ciberfordismo - e suas repercussões nas esferas produtivas, econômicas e sociais no domínio do ultraneoliberalismo. Além disso, este artigo também cumpre o papel proposto de suprir uma lacuna didática e pedagógica, auxiliando os docentes que atuam em disciplinas de teoria da administração e das organizações em suas discussões em sala de aula; este é o principal público para o qual endereçamos o presente texto.

Ainda são escassos os estudos sobre o assunto, conforme constatamos na literatura e na investigação realizada, de modo que, para futuras pesquisas, recomendamos aos investigadores debates em trabalhos sobre nossas proposições, tanto teóricos quanto empíricos, abordando indústrias e organizações de prestação de serviços; bem como centros de investigação nas universidades e pesquisadores voltados ao tema. A Indústria 4.0 traz mais benefícios que prejuízos? Trata-se realmente de uma nova revolução industrial? O ciberfordismo é, de fato, um novo paradigma de produção? Dirigimos, aqui, tais questões à comunidade acadêmica da área, que pode prosseguir esse debate e apresentar suas possíveis divergências.

\section{AGRADECIMENTOS}

Ao CNPQ, pelo apoio financeiro e bolsa produtividade concedida à Profa. Ana Paula Paes de Paula, que viabilizou a pesquisa que originou esse artigo. 


\section{REFERÊNCIAS}

Alves, A. G., Filho, Marx, R., \& Zilbovicius, M. (1992). Fordismo e Novos Paradigmas de Produção: Questões sobre a transição no Brasil. Produção, 2(2), 113-124.

Anderl, R. (2014). Industrie 4.0 - Advanced Engineering of Smart Products and Smart Production. In Proceedings of 19 o International Seminar on High Technology, Piracicaba, SP.

Antunes, R. (1995). Adeus ao Trabalho. São Paulo, SP: Universidade Estadual de Campinas.

Antunes, R. (2019). Riqueza e miséria no Brasil IV. São Paulo, SP: Boitempo.

Antunes, R. (2020a). O privilégio da servidão. O novo proletariado de serviços na era digital. São Paulo, SP: Boitempo.

Antunes, R. (2020b). Trabalho intermitente e uberização do trabalho no limiar da Indústria 4.0. In R. Antunes (Org), Uberização, Trabalho Digital e Indústria 4.0 (pp. 9-22). São Paulo, SP: Boitempo.

Assad, A., Neto, Pereira, G. B., Drozda, F. O., \& Santos, A. P. L. (2018). A busca de uma identidade para a Indústria 4.0. Brazilian Journal of Development, 4(4), 1379-1395.

Astrologo, D., Surbone, A., \& Terna, P. (2019). Il lavoro e il valore all'epoca dei robot. Intelligenza artificiale e non-occupazione. Meltemi, Greece: Milano.

Bitkom, e.V., Vdma, e.V., \& Zvei, e.V. (2016). Implementation strategy Industrie 4.0: report on the results of the Industrie 4.0 plataform. Berlin, Germany: autor.

Caruso, L. (2018). Digital innovation and the fourth industrial revolution: epochal social changes? Al \& Society, 33, 379-392.

Dardot, P., \& Laval, C. (2016). A nova razão do mundo. Ensaio sobre a sociedade neoliberal. São Paulo, SP: Boitempo.

Dowbor, L. (2017). A era do capital improdutivo. São Paulo, SP: Autonomia Literária.

Drath, R., \& Horch, A. (2014). Industrie 4.0: Hit or hype? Industrial Eletronics Magazine, 8(2), 56-58.

Erol, S., Schumacher, A., \& Sihn, W. (2016). Strategic guidance towards Industry 4.0 - a three-stage process model. In Proceedings of International Conference on Competitive Manufacturing, Stellenbosch, South Africa.

Federação das Indústrias do Estado do Rio de Janeiro. (2016). Indústria 4.0. Panorama de Inovação. Recuperado de https://www.firjan.com. $\mathrm{br} /$ publicacoes/publicacoes-de-inovacao/industria-4-0-1.htm

Gentner, S. (2016). Industry 4.0: Reality, Future or just Science Fiction? How to Convince Today's Management to Invest in Tomorrow's Future. CHIMIA International Journal for Chemistry, 70(9), 628-633.

Harvey, D. (1993). A Condição Pós-Moderna (13a ed.). São Paulo, SP: Edições Loyola.

Hermann, M., Pentek, T., \& Otto, B. (2016). Design principles for Industrie 4.0 scenarios. In 49o Hawaii International Conference on Systems Science, Hawaii, EUA.
Jasti, N., \& Kodali, R. (2016). An empirical study for implementation of lean principles in Indian manufacturing industry. Benchmarking: An International Journal, 23(1), 183-207.

Kargermann, H. (2014). Chancen von Industrie 4.0 nutzen. In T. Bauernhansl, M. Hompel \& B. Vogel-Heuser (Eds.), Industrie 4.0 in Production, Automatisierung and Logistik. (pp. 603-614). Wiesbaden, Germany: Springer Vieweg.

Kargermann, H., Wahlster, W., \& Helbig, J. (2013). Recommendations for implementing the strategic initiative Industrie 4.0-Securing the future of German manufacturing industry (Final Report of the Industrie 4.0 Working Group). Recuperado de https://www.bibsonomy.org/ bibtex/25c352acf1857c1c1839c1a11fe9b7e6c/flint63

Khan, A., \& Turowski, K. (2016). A survey of current challenges to opportunities and preparation for Industry 4.0. In Proceedings of the First International Scientific Conference "Intelligent Information Technologies for Industry, Sochi, Russia.

Kubinger, W., \& Sommer, R. (2016). Fourth industrial revolution-impact of digitalization and Internet on the industrial location. Elektrotechnik und Informationstechnik, 133(7), 330-333.

Kupfer, D. (2016, agosto 08). Indústria 4.0 Brasil. Valor Econômico. Recuperado de https://valor.globo.com/opiniao/coluna/industria4-0-brasil.ghtml

Lasi, H., Fettke, P., Kemper, H. G., Feld, T., \& Hoffmann, M. (2014). Industry 4.0. Business \& Informations Systems Enginnering, 6(4), 239-242.

Lima, A. A., \& Pinto, G. S. (2019). Indústria 4.0: um novo paradigma para a indústria. Interface Tecnológica, 16(2), 299-311.

Lipietz, A. O. (1991). Audácia: uma alternativa para o século XXI. São Paulo, SP: Nobel.

Marodin, G., \& Saurin, T. (2013). Implementing lean production systems: research areas and opportunities for future studies. International Journal of Production Research, 51(22), 6663-6680.

Oesterreich, T. D., \& Teuteberg, F. (2016). Understanding the implications of digitisation and automation in the context of Industry 4.0: A triangulation approach and elements of a research agenda for the construction industry. Computers in Industry, 83, 121-139.

Paes de Paula, A. P. (2002). Tragtenberg revisitado: as inexoráveis harmonias administrativas e a burocracia flexível. Revista de Administração Pública, 36(1), 127-144.

Pereira, A., \& Simonetto, E. O. (2018). Indústria 4.0: Conceitos e perspectivas para o Brasil. Revista Universidade Vale do Rio Verde, 16(1), 1-9.

Piccarozzi, M., Aquilani, B., \& Gatti, C. (2018). Industry 4.0 in Management Studies: A Systematic Literature Review. Sustainability, 10, 1-24.

Qin, J., Liu, Y., \& Grosvenor, R. (2016). A Categorical Framework of Manufacturing for Industry 4.0 and beyond. Procedia CIRP, 52, 173-178.

Reichert, J. (Produtor), Benello, J. P. (Produtor), Bognar, S. (Diretor), \& Reichert, J. (Diretor). (2019). American Factory. Culver City, California: Higher Ground Productions. 
Roblek, V., Mesko, M., \& Krapez, A. (2016). A Complex View of Industry 4.0. SAGE Open, 6(2), 1-11.

Rübmann, M., Lorenz, M., Gerbert, P., Waldner, M., Justus, J., Engel, P., ... Harnisch, M. (2015). Industry 4.0: The future of productivity and growth in manufacturing industries. Boston Consulting Group. Recuperado de https://www.bcg.com/pt-br/publications/2015/ engineered_products_project_business_industry_4_future_ productivity_growth_manufacturing_industries

Saltiél, R. M. F., \& Nunes, F. L. (2017). A Indústria 4.0 e o Sistema Hyundai de produção: suas interações e diferenças. In 5o Simpósio de Engenharia de Produção, Joinville, SC.

Sanders, A., Enlangeswaran, C., \& Wulfsberg, J. (2016). Industry 4.0 implies lean manufacturing: research activities in Industry 4.0 function as enablers for lean manufacturing. Journal of Industrial Engineering and Management, 9(3), 811-833.

Santos, B. P., Alberto, A., Lima, T. D. F., \& Charrua-Santos, F. M. B. (2018). Indústria 4.0. Desafios e Oportunidades. Revista Produção e Desenvolvimento, 4(1), 111-124.

Schwab, K. (2016). A quarta revolução industrial. São Paulo: Edipro.

Shah, R., \& Ward, P. (2003). Lean manufacturing: context, practice bundles, and performance. Journal of Operations Management, 21(2), 129-149.

Sigahi, T. F. A. C., \& Andrade, B. C. A, (2017). Indústria 4.0 na perspectiva da Engenharia de Produção no Brasil: Levantamento e síntese de trabalhos publicados em congressos nacionais. In 370 Encontro Nacional de Engenharia de Produção, Joinville, SC.
Silva, R. M., Santos, D. J., Filho, \& Myagi, P. E. (2015). Modelagem de Sistema de Controle da Indústria 4.0 baseada em Holon, Agente, Rede de Petri e Arquitetura orientada a serviços. In 12옹ósio Brasileiro de Automação Inteligente, Natal, RN.

Tenório, F., \& Valle, R. (2013). Fábrica de Software. Rio de Janeiro, RJ: EdFGV.

Tessarini, G., Jr., \& Saltorato, P. (2018). Impactos da Indústria 4.0 na organização do trabalho: uma revisão sistemática da literatura. Revista Produção Online, 18(2), 743-769.

Toni, G. (2019). Nemico (e) immaginario. L'Intelligenza artificiale tra timori e utopie. Recuperado de https://www.carmillaonline. com/2019/10/24/nemico-e-immaginario-lintelligenza - artificialetra-timori-e-utopie/

Tortorella, G. L., Fetterman, D., Giglio, R., \& Borges, G. A. (2018). Implementação da produção enxuta e Indústria 4.0 em empresas brasileiras de manufatura. Revista Empreender e Inovar, 1(1), 1-18.

Tragtenberg, M. (1974). Burocracia e Ideologia. São Paulo, SP: Ática.

Vermulm, R. (2018). Políticas para o desenvolvimento da Indústria 4.0 no Brasil. Brasília, DF: IEDI.

Wood, T., Jr. (1992). Fordismo, Toyotismo e Volvismo: os caminhos da indústria em busca do tempo perdido. Revista de Administração de Empresas, 32(4), 6-18.

Zawadzki, P., \&Żywicki, K. (2016). Smart product design and production control for effective mass customization in the Industry 4.0 concept. Management and Production Engineering Review, 7(3), 105-112.

Ana Paula Paes de Paula

ORCID 0000-0001-8035-472X

Doutora em Ciências Sociais pela Universidade Estadual de Campinas (UNICAMP); Professora Titular da Universidade Federal de Minas Gerais (UFMG). E-mail: appp.ufmg@gmail.com

Ketlle Duarte Paes

ORCID: 0000-0003-4231-0990

Doutora em Administração pela Universidade Federal de Santa Catarina (UFSC); Professora adjunta da Universidade Federal de Rio Grande (FURG).

E-mail: ketllep@yahoo.com.br 